KANSAS JOURNAL of MEDICINE

\section{Treatment of Cardiac Surgical Wounds with Silver Dressings}

Ashlie A. Elver, B.S. ${ }^{1}$, Katy Wirtz, RN, BSN², Jinxiang Hu, Ph.D., ${ }^{1,3}$,

Emmanuel Daon, M.D. ${ }^{1,4}$

${ }^{1}$ University of Kansas School of Medicine, Kansas City, KS

${ }^{2}$ University of Kansas Health System, Kansas City, KS

University of Kansas School of Medicine, Kansas City, KS

${ }^{3}$ Department of Biostatistics and Data Science

${ }^{4}$ Department of Cardiovascular and Thoracic Surgery

Received May 24, 2021; Accepted for publication. July 8, 2021; Published online Nov. 5, 2021 https: /oi.org 10.17161 lijm.voll4.15506

\section{ABSTRACT}

Introduction. Mediastinitis is a deadly surgical site infection (SSI) after cardiac surgery. Although rare, mortality is as high as $47 \%$. Best practices for infection prevention to eliminate this deadly complication must be identified. Surgical dressings impregnated with silver have been shown to reduce SSIs in other surgical specialties. The aim of this study was to determine if the routine use of silver surgical dressings is beneficial to prevent mediastinitis after cardiac surgery.

Methods. A single-center retrospective study was performed on patients who underwent sternotomy from 2016 to 2018 at the University of Kansas Medical Center. Prior to June 2017, all cardiac surgical patients were treated with gauze surgical dressings and designated as Group A. The routine use of silver-impregnated surgical dressings was implemented in June 2017; patients after this change in practice were designated as Group B. Patient characteristics and rates of deep and superficial sternal wound infections (SWI) were compared.

Results. There were 464 patients in Group A and 505 in Group B. There were seven SWIs in Group A (7/464, 1.5\%) and five in Group B $(5 / 505,1 \% ; p=0.57)$. Of these, there was one deep SWI per group (p $=0.61$ ) and six superficial SWIs in Group A compared to four in Group B ( $p=0.74)$. Severe COPD was higher in Group A $(p=0.04)$ and peak glucose was higher in Group B ( $p=0.02)$.

Conclusions. The analysis conferred no benefit with silver-impregnated surgical dressings to prevent mediastinitis. Choice of gauze surgical dressings may be preferable to reduce cost.

\section{Kans J Med 2021;14:269-272}

\section{INTRODUCTION}

Surgical site infection (SSI) is a burdensome healthcare-associated infection (HAI) affecting nearly all surgical operations, with potentially devastating outcomes. ${ }^{1}$ Specifically in cardiac surgery, patients are susceptible to superficial and deep sternal wound infections (SWI), noted by some to occur in $8.49 \%$ of sternotomies. ${ }^{2}$ Deep sternal wound infection (DSWI), or mediastinitis, is the most serious SWI and has mortality rates reported as high as $47 \% .^{3}$ Many efforts were made to optimize infection prevention strategies that became standard of care resulting in a $32 \%$ decrease in infection rates from 2008 to $2012 .{ }^{4}$ Some of these strategies included skin and nares decontamination, antibiotic prophylaxis, strict perioperative glucose control, and surgical closure techniques (i.e., figure-of-eight, Robicsek). ${ }^{5,6}$ Despite this, the incidence of DSWI remains unacceptably high at $0.5 \%$ to $6 \%$ and warrants further investigation.? $^{\text {? }}$

Contamination of the sternal wound by normal skin flora is an important route for infection in the postoperative period. Pathogens can gain access to deeper tissues when dehiscence is present due to the normal breathing mechanics at the destabilized wound. ${ }^{8-12}$ Theoretically, reducing the bioburden around the incision in the postoperative period could interrupt this process and allow time for wound healing. Guidelines for infection prevention focus on the pre- and intra-operative periods, while less clear guidance is given in the postoperative period. In this situation, exogenous routes seeding deep tissue infections after leaving the operating room deserve further consideration.

One idea gaining popularity in postoperative wound care is the use of silver surgical dressings to harness the natural bactericidal and bacteriostatic properties of silver. ${ }^{13}$ Silver has long been used successfully in device coating and chronic wound and burn care, and more recently has shown promising results to prevent SSI. ${ }^{14-21}$ The mechanism of silver-impregnated surgical dressings presents an opportunity to decontaminate the incision while the sternum heals. Early reports were compelling, and one study noted zero cases of mediastinitis after replacing gauze with silver dressings. But the reproducibility of these findings was variable, and the pursuit of high-quality data slowed down. ${ }^{22-25}$ However uncertain, the potential to save one patient from suffering this complication instituted a department wide change to use silver dressings in all cardiothoracic surgical patients.

Cost-conscious care is a principle of high-value healthcare. Benefitcost analysis evaluates the benefits of interventions with their costs, such as postoperative silver dressings at this institution. The immediate cost of silver dressings is $\$ 26.82$ for each sternal dressing. The potential benefits are mitigating future costs of mediastinitis and reduced morbidity and mortality for patients. The aim of this study was to evaluate this intervention and its ability to achieve the intended goal of reducing postoperative complications at this institution.

\section{METHODS}

This single-center study was approved by the institutional review board at the University of Kansas Medical Center. A retrospective cohort study was performed on adults 18-years-old and older who underwent sternotomy for cardiac surgery from June 2016 to June 2018. Patients with active infection at the time of operation and those undergoing open heart transplant were excluded due to higher susceptibility to infections. Left ventricular assist device placements were excluded because sternal incisions are not uniformly performed in these cases. Sternotomy incisions were treated with gauze dressings (GD) in all patients before June 2017; this was Group A and served as the control group. Sternotomy incisions after June 2017 were treated with silverimpregnated dressings (SD) after a department wide change in practice was implemented; this was Group B and served as the treatment group. All operations were performed by board-certified cardiothoracic surgeons and patients received the same perioperative infection prevention protocol aligned with institutional standards. GD used in Group A were replaced on postoperative day two and removed on postoperative day three or until wound was dry. CarraKlenz ${ }^{\mathrm{TM}}$ wound cleanser (Medline 
Industries, Northfield Illinois) was used during dressing changes. Commercially available SD used in Group B were removed on postoperative day seven as recommended by the manufacturer (Argentum Medical, Geneva Illinois).

Sternal wound infections were diagnosed by surgeons according to the criteria from the U.S. Centers for Disease Control and Prevention. ${ }^{26}$ Superficial sternal wound infection (SSWI) involved tissue above the fascial plane with at least one of the following: 1) purulent drainage; 2) organisms isolated from the wound; 3 ) tenderness, swelling, or heat present and wound opened by surgeon; or 4) diagnosis by surgeon. DSWI, or mediastinitis, involved tissue below the fascial plane (with or without infected retrosternal space) and met at least one of the following: 1) purulent drainage; 2) wound dehiscence or opened by surgeon with organisms identified in mediastinal tissue or fluid and fever (> $38^{\circ} \mathrm{C}$ ) or tenderness present; or 3) evidence of infection on gross anatomical or histopathologic exam.

Data were collected using electronic medical record and the Society of Thoracic Surgeons database. Patient demographics including age, sex, body mass index (BMI), smoking history, and comorbidities were collected. Severe chronic obstructive pulmonary disease (COPD) was defined as $\mathrm{FEV}_{1}<50 \%$ of predicted value. Recorded operative details included cardiac bypass time, valve operation, blood products, peak lab values, ventilation time, and length of stay.

Data were analyzed using SAS statistical software version 9.4 (SAS Institute, Cary, NC). Continuous and normally distributed data were presented as mean with standard deviation and categorical data were presented as percentages. Fisher exact test was used for analysis of categorical data and student t-test was used for analysis of continuous variables.

\section{RESULTS}

There were 464 patients in Group A and 505 patients in Group B. There were significantly more patients with severe COPD in Group A (39/464, 8.4\%) compared to Group B $(26 / 505,5.1 \%$; p = 0.04). There were no statistical differences in other demographic variables including age (62.2 \pm 13 years vs. $61.2 \pm 13.3$ years in Group B; $p=0.23)$, female $\operatorname{sex}(128 / 464,27.6 \%$ vs. $160 / 505,31.7 \%$ in Group B; $p=0.16)$, BMI (30 $\pm 5.6 \mathrm{~kg} / \mathrm{m}^{2}$ vs. $30 \pm 6.3 \mathrm{~kg} / \mathrm{m}^{2}$ in Group B; p = 0.99), Hemoglobin AlC $(6 \pm 1.7 \mathrm{mg} / \mathrm{dL}$ vs. $6.1 \pm 1.7 \mathrm{mg} / \mathrm{dL}$ in Group B; $\mathrm{p}=0.41)$, current smokers (260/464, $56 \%$ vs. $291 / 505,57.6 \%$ in Group B; p = 0.62), diabetes (177/464, 38.1\% vs. 170/505 in Group B, 33.7\%; p = 0.15), hypertension (386/464, 83.2\% vs. 410/505, 81.2\% in Group B; $\mathrm{p}=0.42)$, dyslipidemia $(361 / 464,77.8 \%$ vs. $400 / 505,78.2 \%$ in Group B; $p=0.59)$, dialysis (17/464, $3.7 \%$ vs. $13 / 5052.6 \%$ in Group B, p = 0.33), emergent procedures $(35 / 464,7.5 \%$ vs. $44 / 505,8.7 \%$ in Group B; $\mathrm{p}=0.51)$, or valvular procedures (190/464, 41\% vs. 193/505, 38.2\% in Group B; $\mathrm{p}=0.38$ ).

Average intraoperative peak glucose levels were significantly higher in Group B (186.9 $\pm 62.1 \mathrm{mg} / \mathrm{dL})$ compared to Group A (179.1 $\pm 41.3 \mathrm{mg} /$ $\mathrm{dL} ; \mathrm{p}=0.02$ ). All other operative characteristics were not statistically different, including cardiac bypass time (106.5 minutes \pm 46.6 vs. 109.1 minutes \pm 53.2 in Group B; $\mathrm{p}=0.41$ ), peak creatinine $(1.6 \mathrm{mg} / \mathrm{dL} \pm 1.6$ vs. $1.5 \pm 1.5 \mathrm{mg} / \mathrm{dL}$ in Group B; $\mathrm{p}=0.45$ ), ventilation time (17.4 hours \pm 46.9 vs. $20.6 \pm 48.6$ hours in Group B; $\mathrm{p}=0.30$ ), blood products $(186 / 464$, $40 \%$ vs. 189/505, 37.4\% in Group B; $p=0.40$ ), or length of stay (8.1 days \pm 5.9 vs. 7.6 days \pm 5.3 in Group B; $\mathrm{p}=0.19$ ).
KANSAS JOURNAL of MEDIC INE

SILVER DRESSINGS IN CARDIAC SURGERY

continued.

Table 1. Comparison of baseline characteristics between patients who received gauze surgical dressings before June 2017, and patients who received silver-impregnated surgical dressings after June 2017.

\begin{tabular}{|l|c|c|c|}
\hline & $\begin{array}{c}\text { Gauze dressings } \\
\text { Group A, N }=464\end{array}$ & $\begin{array}{c}\text { Silver dressings } \\
\text { Group B, N =505 }\end{array}$ & p value $^{\text {a }}$ \\
\hline Characteristics & \multicolumn{2}{|c|}{ Mean ( \pm Standard Deviation) } & \\
\hline Age, years & $62.2(13)$ & $61.2(13.3)$ & 0.23 \\
\hline BMI, kg/m² & $30(5.6)$ & $30(6.3)$ & 0.99 \\
\hline Hemoglobin AlC, mg/dL & $6(1.7)$ & $6.1(1.7)$ & 0.41 \\
\hline Cardiac bypass time, min & $106.5(46.6)$ & $109.1(53.2)$ & 0.41 \\
\hline Peak glucose, mg/dL & $179.1(41.3)$ & $186.9(62.1)$ & $0.02^{\mathrm{a}}$ \\
\hline Peak creatinine, mg/dL & $1.6(1.6)$ & $1.5(1.5)$ & 0.45 \\
\hline Ventilation time, hour & $17.4(46.9)$ & $20.6(48.6)$ & 0.30 \\
\hline Length of stay, days & $8.1(5.9)$ & $7.6(5.3)$ & 0.19 \\
\hline & & & \\
\hline Sex, female & $128(27.6)$ & $160(31.7)$ & 0.16 \\
\hline Current smoker & $260(56)$ & $291(57.6)$ & 0.62 \\
\hline Severe COPD ${ }^{\mathrm{b}}$ & $39(8.4)$ & $26(5.1)$ & $0.04^{\mathrm{a}}$ \\
\hline Diabetes & $177(38.1)$ & $170(33.7)$ & 0.15 \\
\hline Hypertension & $386(83.2)$ & $410(81.2)$ & 0.42 \\
\hline Dyslipidemia & $361(77.8)$ & $400(78.2)$ & 0.59 \\
\hline Dialysis & $17(3.7)$ & $13(2.6)$ & 0.33 \\
\hline Emergent operation & $35(7.5)$ & $44(8.7)$ & 0.51 \\
\hline Valve procedure & $190(41)$ & $193(38.2)$ & 0.38 \\
\hline Blood products & $186(40)$ & $189(37.4)$ & 0.40 \\
\hline
\end{tabular}

${ }^{a} \mathrm{p}<0.05$, statistically significant

${ }^{\mathrm{b}} \mathrm{FEV}_{1}<50 \%$ of predicted

SWI developed in seven patients in Group A $(7 / 464,1.5 \%)$ and in five patients in Group B $(5 / 505,1 \%$; $\mathrm{p}=0.57)$. Of these, six wounds in Group A and four wounds in Group B were classified as superficial ( $\mathrm{p}=$ 0.74). One wound in both Group A and Group B was classified as deep ( $\mathrm{p}=0.61$; Table 2).

Table 2. Incidence of sternal wound infections (SWI) in patients who received gauze surgical dressings before June 2017, and patients who received silver-impregnated surgical dressings after June 2017.

\begin{tabular}{|c|c|c|c|}
\hline & $\begin{array}{c}\text { Gauze dressings } \\
\text { Group A, N = 464 }\end{array}$ & $\begin{array}{c}\text { Silver dressings } \\
\text { Group B, N = 505 }\end{array}$ & p value \\
\hline & \multicolumn{2}{|c|}{$\mathrm{n}(\%)$} & \\
\hline Total SWI & $7(1.5)$ & $5(1)$ & 0.57 \\
\hline Deep & $1(0.4)$ & $1(0.2)$ & 0.61 \\
\hline Superficial & $6(1.3)$ & $4(0.8)$ & 0.74 \\
\hline
\end{tabular}

${ }^{\mathrm{a}} \mathrm{p}<0.05$, statistically significant 
KANSAS JOURNAL of MEDICINE

SILVER DRESSINGS IN CARDIAC SURGERY

continued.

\section{DISCUSSION}

The interest in silver dressings in cardiac surgery began when Huckfeldt reported a reduction in SWIs with SD down to zero compared to traditional gauze in adult cardiac patients. ${ }^{25}$ Adding to the interest, Totaro demonstrated the addition of SD in patients with mediastinitis refractory to wound vacuum-assisted closure caused wound cultures to turn negative. ${ }^{27}$ This prompted further investigation. In 2016, a randomized control trial was conducted in pediatric patients undergoing sternotomy for cardiac surgery to compare silver and gauze dressings. No infections occurred in either group and the authors concluded silver and gauze were equally effective. ${ }^{23}$ More recently, Raman also reported no difference between silver and gauze in a single center retrospective study of adult cardiac patients. ${ }^{22}$ The findings reported in the literature were variable, making the clinical significance of SD unclear.

Our study did not indicate benefit with the use of SD to prevent mediastinitis or even superficial sternal infections. The incidence of infection in our study population was similar to what was reported in the literature, and like Raman, ${ }^{22}$ we were not able to reproduce the promising results reported by Huckfeldt ${ }^{25}$ in 2004 . This may suggest institutional-specific bias present in Huckfeldt's study. However, without randomized controlled trials in the adult cardiac population, the benefit remains unclear.

Our study results could have been influenced by the differences between study groups noted at baseline. Patients with COPD are known to be at increased risk of developing SWI. ${ }^{28,29}$ We had significantly more patients with severe COPD in Group A, which could have exacerbated the observed benefit in Group B. Strict glycemic control during the perioperative period is known to reduce the risk of developing SWI ${ }^{28-30}$ We noted a significantly higher peak glucose level in Group B compared to the control, which could have underestimated benefit of SD. However, the peak glucose level did not exceed the level associated with elevated risk $\left(>200 \mathrm{mg} / \mathrm{dL}\right.$ ). ${ }^{31}$ Thus, we do not believe either of these differences would have changed the results in a meaningful way.

Our study was limited by its retrospective nature and lack of randomization. Over the duration of the study, it was possible that small changes in practice could have introduced confounders. The overall incidence of mediastinitis was low in both study groups making it difficult to draw conclusions in this retrospective study. This was a single-center study and results may not be generalizable, although incidence was like that of the general population.

\section{CONCLUSIONS}

A retrospective analysis assessed the use of silver-impregnated surgical dressings compared to gauze surgical dressing in hopes of preventing mediastinitis. The analysis showed no benefit with the use of silver-impregnated surgical dressings. Based on these results, treatment of the sternal incision with gauze may be preferred to reduce cost. Further investigation of optimal wound care during the postoperative period is needed in the effort to eliminate this costly and deadly complication.

\section{REFERENCES}

${ }^{1}$ U.S. Centers for Disease Control and Prevention. Acute care hospital surveillance for surgical site infections. http://www.cdc.gov/nhsn/acutecare-hospital/ssi/index.html. Accessed June 26, 2021.

${ }^{2}$ Edwards JR, Peterson KD, Mu Y, et al. National Healthcare Safety Network (NHSN) report: Data summary for 2006 through 2008, issued December 2009. Am J Infect Control 2009; 37(10):783-805. PMID: 20004811.

El Oakley RM, Wright JE. Postoperative mediastinitis: Classification and management. Ann Thorac Surg 1996; 61(3):1030-1036. PMID: 8619682.

4 U.S. Centers for Disease Control and Prevention. 2014 National and State Healthcare-Associated Infections Progress Report. 2016. https://www.cdc. gov/hai/progress-report/index.html. Accessed October 1, 2020.

${ }_{5}^{5}$ Lazar HL, Salm TV, Engelman R, Orgill D, Gordon S. Prevention and management of sternal wound infections. J Thorac Cardiovasc Surg 2016; 152(4):962-972. PMID: 27555340.

6 Association for Professionals in Infection Control and Epidemiology. Guide for the Prevention of Mediastinitis Surgical Site Infections Following Cardiac Surgery. 2008. https://www.apic.org/eliminationguides. Accessed October 1, 2020.

7 Hever P, Singh P, Eiben I, Eiben P, Nikkhah D. The management of deep sternal wound infection: Literature review and reconstructive algorithm. JPRAS Open 2021; 28:77-89. PMID: 33855148.

${ }^{8}$ Goh SSC. Post-sternotomy mediastinitis in the modern era. J Card Surg 2017; 32(9):556-566. PMID: 28833518.

9 von Eckardstein AS, Lim CH, Dohmen PM, et al. A randomized trial of a skin sealant to reduce the risk of incision contamination in cardiac surgery. Ann Thorac Surg 2011; 92(2):632-637. PMID: 21704290.

${ }_{10}$ Mossad SB, Serkey JM, Longworth DL, Cosgrove DM 3rd, Gordon SM. Coagulase-negative staphylococcal sternal wound infections after open heart operations. Ann Thorac Surg 1997; 63(2):395-401. PMID: 9033307.

11 Gårdlund B, Bitkover CY, Vaage J. Postoperative mediastinitis in cardiac surgery - microbiology and pathogenesis. Eur J Cardiothorac Surg 2002; 21(5):825-830. PMID: 12062270.

${ }^{12}$ Losanoff JE, Richman BW, Jones JW. Disruption and infection of median sternotomy: A comprehensive review. Eur J Cardiothorac Surg 2002; 2l(5):831-839. PMID: 12062271.

${ }^{13}$ Kumar Pandian SR, Deepak V, Kalishwaralal K, Viswanathan P, Gurunathan S. Mechanism of bactericidal activity of silver nitrate - A concentration dependent bi-functional molecule. Braz J Microbiol 2010; 4l(3):805-809. PMID: 24031558.

${ }^{14}$ Krieger BR, Davis DM, Sanchez JE, et al. The use of silver nylon in preventing surgical site infections following colon and rectal surgery. Dis Colon Rectum 2011; 54(8):1014-1019. PMID: 21730792.

${ }_{15}$ Epstein NE. Do silver-impregnated dressings limit infections after lumbar laminectomy with instrumented fusion? Surg Neurol 2007; 68(5):483-485. PMID: 17961738.

16 Zegelman M, Guenther G, Waliszewski M, et al. Results from the International Silver Graft Registry for high-risk patients treated with a metallic-silver impregnated vascular graft. Vascular 2013; 21(3):137-147. PMID: 23508393.

${ }_{17}$ Ogbemudia AO, Bafor A, Edomwonyi E, Enemudo R. Prevalence of pin tract infection: The role of combined silver sulphadiazine and chlorhexidine dressing. Niger J Clin Pract 2010; 13(3):268-271. PMID: 20857782.

${ }^{18}$ Nherera L, Trueman P, Roberts C, Berg L. Silver delivery approaches in the management of partial thickness burns: A systematic review and indirect treatment comparison. Wound Repair Regen 2017; 25(4):707-721. PMID: 28742235.

19 Moir J, Serra MP. The use of silver nitrate in wound management. Ann Ital Chir 2012; 83(1):45-48. PMID: 22352216.

20 Storm-Versloot MN, Vos CG, Ubbink DT, Vermeulen H. Topical silver for preventing wound infection. Cochrane Database Syst Rev 2010; (3):CD006478. PMID: 20238345.

${ }^{21}$ Siah CJ, Yatim J. Efficacy of a total occlusive ionic silver-containing dressing combination in decreasing risk of surgical site infection: An RCT. J Wound Care 2011; 20(12):561-568. PMID: 22240882.

${ }^{22}$ Raman V, Thompson-Brazill KA, Kane K, et al. Silver-impregnated dressing does not decrease incidence of surgical site infection after adult cardiac surgery. Innovations (Phila) 2018; 13(4):296-299. PMID: 30124586.

23 Staveski S, Abrajano C, Casazza M, et al. Silver-impregnated dressings for sternotomy incisions to prevent surgical site infections in children. Am J Crit Care 2016; 25(5):402-408. PMID: 27587419.

${ }^{24}$ Schwartz J, Goss S, Facchin F, et al. A prospective two-armed trial assessing the efficacy and performance of a silver dressing used postoperatively on high-risk, clean surgical wounds. Ostomy Wound Manage 2014; 60(4):3040. PMID: 24706401. 
25 Huckfeldt R, Redmond C, Mikkelson D, Finley PJ, Lowe C, Robertson J. A clinical trial to investigate the effect of silver nylon dressings on mediastinitis rates in postoperative cardiac sternotomy incisions. Ostomy Wound Manage 2008; 54(10):36-41. PMID: 18927482.

26 U.S. Centers for Disease Control and Prevention. The NHSN Surgical Site Infection Event (SSI). 2021. https://www.cdc.gov/nhsn/pdfs/ pscmanual/9pscssicurrent.pdf. Accessed June 26, 2021.

27 Totaro P, Rambaldini M. Efficacy of antimicrobial activity of slow release silver nanoparticles dressing in post-cardiac surgery mediastinitis. Interact Cardiovasc Thorac Surg 2009; 8(1):153-154. PMID: 18948308.

28 Risnes I, Abdelnoor M, Almdahl SM, Svennevig JL. Mediastinitis after coronary artery bypass grafting risk factors and long-term survival. Ann Thorac Surg 2010; 89(5):1502-1509. PMID: 20417768.

29 Phoon PHY, Hwang NC. Deep sternal wound infection: Diagnosis, treatment, and prevention. J Cardiothorac Vasc Anesth 2020; 34(6):1602-1613. PMID: 31623967.

${ }^{30}$ Furnary AP, Wu Y. Eliminating the diabetic disadvantage: The Portland Diabetic Project. Semin Thorac Cardiovasc Surg 2006; 18(4):302-308. PMID: 17395026.

31 Trick WE, Scheckler WE, Tokars JI, et al. Modifiable risk factors associated with deep sternal site infection after coronary artery bypass grafting. J Thorac Cardiovasc Surg 2000; 119(1):108-114. PMID: 10612768.

Keywords: standard of care, mediastinitis, surgical wound infection, cardiac surgical procedures, postoperative period
KANSAS JOURNAL of MEDIC INE SILVER DRESSINGS IN CARDIAC SURGERY continued. 